\title{
Histopathological study of Schistosoma mansoni infection in the murine model using the PC (Pará) and LILA (Maranhão) strains
}

\author{
Igor da Costa Lopes, Vanessa RC dos Santos, Vera LR Barros Souza, \\ Izabel R de C Rodrigues*/+
}

\author{
Seção de Patologia *Seção de Parasitologia, Instituto Evandro Chagas, Rodovia BR-316, km 7 s/n, \\ Levilândia, 67030-000 Ananindeua, PA, Brasil
}

\begin{abstract}
Experimental models of Schistosoma mansoni infections in mammals have contributed greatly in understanding the pathology and pathogenesis of human infection. The absence of earlier reviews regarding specific strains of the Amazon region prompted research, which the main objective was to describe histopathological lesions in different phases of schistosomiasis in a murine model using PC (Pará) and LILA (Maranhão) S. mansoni strains. One hundred and eighty young female albino swiss mice (Mus musculus) were used and were randomly divided into five groups (PC-01, PC-02, LILA-01, LILA-02, and controls), according to the number of cercariae injected and the strain adopted. Animals were sacrificed in predetermined periods $(35,56,112,156$, and 180 days) in an attempt to follow the evolution of the disease in the histological sections of their tissues at different phases of infection. Our findings were compatible with the data already described by others authors using different strains of S. mansoni, making it possible to identify some peculiarities, which are discussed in this work. In conclusion, the strains of parasite used did not modify the histopathological findings in the tissues of infected mice in any significant way when compared with the results of other studies using different strains.
\end{abstract}

Key words: Schistosoma mansoni - histopathology - granuloma - strains

The experimental infection by Schistosoma mansoni in laboratory animals has been frequently used as a model for the analysis of pathological and physiopathological studies in human infection (Andrade et al. 1985, Carvalho et al.1986, Coelho et al. 1989, Cheever et al. 2002).

Experimental studies of some strains have shown differences regarding the quantity of eggs in the phase of oviposition, infectivity, and pathogenicity and these factors are not worm-burden dependent (Teixeira et al. 2001). When different results are obtained in experimentals with $S$. mansoni, these discrepancies are usually attributed to difference in the parasite strain used. Some experiments have used a Puerto Rico strain (Andrade et al. 1985). In Brazil, each investigator uses his regional strain and it is frequently necessary to compare the results of studies with Puerto Rico and Brazilian strains (Andrade et al. 1985, Coelho et al. 1989). The paucity of studies in the Amazonian area prompted the following investigation, with the objective of describing the histopathological findings at different phases of experimental infection by two strains PC (PA) and LILA (MA) of S. mansoni in laboratory mice.

\section{MATERIALS AND METHODS}

Young, female, albino Swiss mice of 30 days old were supplied by the Animal House of the Evandro Chagas

Finnancial support: Secretaria de Vigilância em Saúde - Instituto Evandro Chagas-MS

+Corresponding author: izabelrodrigues@iec.pa.gov.br

Received 25 May 2006

Accepted 26 June 2006
Institute (IEC) and they were adapted to the Schistosomiasis Laboratory, 15 days before the iniciation of the experiment. They were maintained in a room at approximately $28^{\circ} \mathrm{C}$, and water and mouse pellet diet were provided $a d$ lib

A total of sixty mice were infected with recently eliminated cercariae of PC (PA) strain of $S$. mansoni. Thirty of these animals received 60 cercariae $/ 0.1 \mathrm{ml}$ standardized in the study (Group PC-01) and the other 30 received approximately 100 cercariae/ $0.1 \mathrm{ml}$ (Group PC-02). In similar fashion 60 animals were infected with cercariae of LILA (MA) strain, obtained at the same time from the same group of snails. Thirty of these animals received 60 cercariae/ 0.1 $\mathrm{ml}$ (Group LILA-01) and the others, approximately 100 cercariae/0.1 ml (Group LILA-02). Twenty non-infected mice served as a control group. In our investigation we choose to study five phases of infection: (1) the prepatent phase: 24 animals (6 of Group PC-01, 6 of Group PC-02, 6 from Group LILA-01, and 6 from Group LILA-02) were sacrificed 5 weeks post-infection (p.i.); (2) the acute phase: 24 animals ( 6 animals from each group) were killed 8 weeks p.i.; (3) the intermediate phase: 24 animals (6 animals from each group) were sacrificed 16 weeks p.i.; (4) the chronic phase: 24 animals ( 6 animals from each group) were killed 22 weeks p.i.; (5) the late phase: 24 animals (6 animals from each group) were sacrificed 26 weeks p.i.

At each infection phase, four animals from the control group were sacrificed.

Direct fecal examination of each mouse was followed by perfusion (Duvall \& DeWitt 1967) for recovery and counting of adult worms. Liver, lungs, spleen, and intestines were removed for macroscopic study and preparation of histological sections. Sections were stained by hematoxylin and eosin, Gomori's trichrome stain for collagen content, reticulin staining for reticular fibers, 
Verhoeff's staining for elastic fibers, Gram and Giemsa staining for bacterial colonies.

The diameter of hepatic granulomas was measured using a Zeiss ocular micrometer and a Zeiss binocular microscope with a $\times 40$ objective.

The results were classified in evaluated fiches of analyses and submitted to the statistic test $\mathrm{T}$ of Student and Meta-analysis with several combined proportions (BioEstat 3.0).

\section{RESULTS}

Use of the different strains of $S$. mansoni from Pará (PC) and Maranhão (LILA) did not greatly modify the histopathological findings during the five phases of infection in the tissues of infected mice, and were similar to those seen by other authors in studies using different strains.

The histopathological findings are discussed and summarized together with the illustrations.

The mortality among infected mice in this study was $35 \%$, with no significant differences regarding the strains or the number of cercariae used to infect the animals. The majority of the animals that died during the experiment were found in an advanced stage of decomposition and tissue autolysis, which made histopathological analysis difficult or impossible. Among the few dead mice it was possible to examine, probable sepsis was observed with inflammatory reaction in various organs and the formation of hepatic abscesses with intense polymorphonuclear infiltrations and presence of pyocytes. Staining by Gram's and Giemsa's methods allowed us to identify innumerable Gram-positive Staphylococcus bacterial colonies adhered to abscesses.

The relationship of schistosomiasis and hepatic pyogenic abscess has been well documented in medical literature from clinical (Lambertucci et al. 1997, 2001) and experimental studies (Teixeira et al. 2001) with Staphylococcus aureus as the main agent.

A significant liver enlargement was observed in infected mice after the eighth week of infection. It was seen in the four groups when livers were compared with those of the control group of animals.

Hepatic granulomas showed the greatest diameter in mice at the acute phase of infection, followed by the immunomodulation and decrease in size of values in the subsequent stages (Table).

In considering the hepatic alterations occured during the pre-patent phase, we observed the frequent forma- tion of necrotic-exudative reactions with variation in its occurrence among the two different strains. In the PC strain, eggs were absent in the center of such lesions, but they could be seen in these parenchyma alterations in mice infected with the LILA strain.

In mice at the late phase of infection, with both $\mathrm{PC}$ and LILA strains, there could be seen the classic description of granulomas in cure by fibrosis, with substitution of great part of the exudates by conjunctive neoformation and reduction in size evidenced in infected animals by both strains used in the study.

Gomori's trichrome stain allowed one to follow the dynamics involving collagen fibers; in addition, at the late phase of infection in mice of group LILA-01, there could be seen an increased and intensely fibrosed portal system, with the production of long septic approaching other portal veins, and disrupting the hepatic structure (Fig. 1C).

The participation of reticular fibers in the development of the granulomatous reaction seen in this study was similar to that described by Silva et al. (2000)

\section{DISCUSSION}

In work published by Carvalho et al. (1986), the maximum weight of mice found in the study at ten weeks p.i. had decreased. In these authors study, however, healthy mice were not used. Coelho et al. (1989) made the same observation and recorded a notable reduction in the dimensions of granulomatous reactions at 12 weeks p.i.

Our measurements of hepatic granulomas differed from those obtained by Carvalho et al. (1986), Coelho et al. (1989), and Domingo and Warren (1968), presumably due to factors such the immunological reaction of the host to different strains, number of cercariae used to infected mice, different dates of sacrifice, and differing method of measuring the granulomas.

Andrade and Warren (1964) and Raso (2000) described granulomas as initially bulky, with intense cellularity (predominently macrophages, lymphocytes, and eosinophyls); later, the exudate decreases and is substituted by conjunctive tissue until the formation of a fibroid nodule. Although the egg output continues, the newly formed granulomas were smaller and paucicelular. These findings were also observed in our mice infected with the PC and LILA strains, suggesting their occurrence regardless of the strain used. (Figs 1A, B).

The idea that $S$. mansoni eggs have little participation in the necrotic-exudative reactions seen in the pre-patent

TABLE

Dimension of granulomas $(\mu \mathrm{m})$, in liver of mice infected by PC (PA) and LILA (MA) strains of Schistosoma mansoni, in different phases of infection

\begin{tabular}{lccccc}
\hline Group & Pre-patent & Acute & Intermediate & Chronic & Late \\
\hline PC-01 & - & 557.3 & $274^{a}$ & 243.5 & $202^{a}$ \\
LILA-01 & 202 & 541.6 & $277^{a}$ & $190.7^{a}$ & 194 \\
PC-02 & - & 498.5 & $260.8^{a}$ & 166 & 211.6 \\
LILA-02 & 255 & $503.6^{a}$ & $251.7^{a}$ & 229 \\
\hline
\end{tabular}

Source: Work protocol; $a$ : $\mathrm{P} \leq 0.05$ (Student T test). 

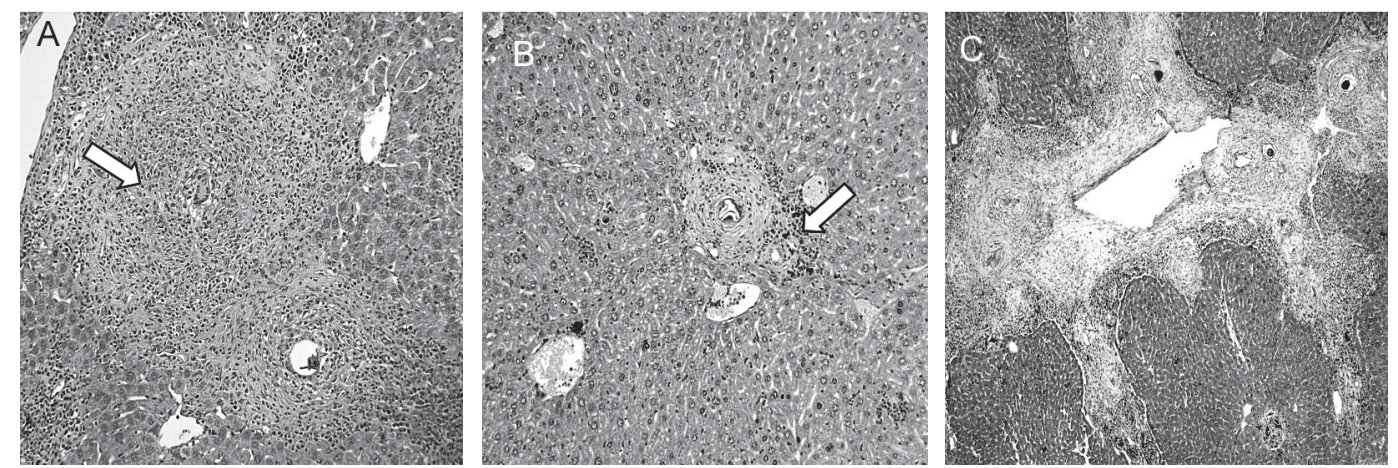

Fig. 1: histopatological findings in hepatic experimental infection by Schistosoma mansoni. A: concentric granuloma in acute phase, with central gigantic cell (arrow), H\&E, 100×; B: granuloma showing a scar in the chronic phase, with peripheral pigment (arrow), H\&E, 100×; C: "Pipe stem cirrhosis" in delayed phase, TG, 40×.

phase has been defended by Raso (2000) and Lichtenberg (1962); these authors do not attribute the role of eggs in the production of antibodies but consider this to be due to reactions to cercariae, schistossomules and adult worms.

Andrade and Azevedo (1987) however assert that, before the egg-depositing, only small and isolated changes could be seen in the hepatic parenchyma of mice infected with cercariae of the Feira de Santana (BA) strain of $S$. mansoni. Severe alterations of reactional hepatitis and necrotic-exudative reactions were only first observed on the 37th day of infection, when the first eggs of the trematode were found in the liver. The association of S. mansoni eggs and necrotic exudative reaction was also noted in our study, when considering lesions generated by the LILA strain during this stage of infection. Added to these observations is the frequent and characteristic presence of pigments, extremely common in that phase, representative of ingested erythrocytes digestion eliminated by the adult worms and is eliminated in the hepatic circulation, together with the appearance of ductular proliferation, during the last three phases of the illness. It suggests the installation of a "shunt" mechanism to compensate the possible elevation of the hydrostatic pressure in the portal system (Andrade et al. 1964, Cheever et al. 2002).

Periportal fibrosis of hepatoesplenic schistosomiasis is a dynamic process that results from unbalance between synthesis and degradation of conjunctive tissue components, and it is possible that the soluble antigens of eggs are mainly responsible for this conjunctive neo-formation. This is compatible with the reports of "clay-pipestem fibrosis", described by Symmers, apud Raso (2000), and defended by other authors (Cheever et al. 2002). The absence of this lesion in our mice housing worms of the PC strain could be due to the minimum number of viable animals in the last stages of the experiment or because this strain is less fibrogenic compared with the Maranhão strain (LILA). While we believe that the first suggestion is the most acceptable, a precipitated conclusion is best avoided, and subsequent studies, using a larger number of animals, will be necessary to explain this finding.

The role of reticular fibers in the evolution of granulomatous reaction was also well established in this work. In initial phases of the process, these fibers constitutes one of the main components of the extracellular matrix, originating as an extensive net of dense fibrils in the areas of granuloma installation. With the progression of the disease, there is a compacting tendency and the confluence of these constituents of the matrix, with the fibrils becoming less numerous in the chronic phases and termination of the infection.

In the work published by Andrade and Freitas (1991), the elastic hyperplasia, which is frequently observed in hepatic biopsies of hepatosplenic patients, can play an important role in pathogenesis of portal hypertension and remodeling of the extracellular matrix. This picture differs from that recorded by Silva et al. (2000), who were able to detect discrete elastic fibers in some hepatic granulomas of a few infected mice, in the chronic phase of the experiment. These were notably absent in the acute and intermediate phases of infection. The results of our studies were similar to those of Andrade and Freitas (1991), namely, with no picture of elastic hyperplasia throughout the experiment. In fact, the involvement of elastic fibers in portal hypertension has not yet been shown with absolute precision in hypertension portal pathogenesis of the murine model.

The histopathological alterations observed in the lungs are compatible with those previously described in studies using strains which were different to those used in this study. Raso (2000) showed that, in laboratory animals, lesions are inconstant and discreet, including congestion and rupture of alveolar capillaries during the phase prior to egg production in the trematode life-cycle. After the egg-positioning, the tissue alterations consist of an intense spread of eggs with granuloma formation most commonly in and around the small arteries (Fig. 2A). In our work, such alterations were seen mainly in mice infected with the LILA strain of S. mansoni, which produced a diffuse inflammatory reaction of the lung tissue in the intermediate phase of infection, probably in order to destroy the eggs in the systemic circulation. Raso (2000) called attention to the greatest frequency of such egg destruction in animals with the hepatosplenic form of infection, in which the escape from eggs to lungs by the portal circulation is greater, because of probable collateral opening provoked by portal hypertension. 
Our observation that eggs were visible in lung tissue serosa of mice from the 5 th week of infection with the PC strain differs from those of Souza Vidal et al. (1993) who detected them in the lungs only after ten weeks p.i. This is probably because the PC strain produces a larger load of infection, and this indicates variation in the behaviour of different strains of S. mansoni.

Regarding histopathology of the spleen, this organ showed precocious enlargement in its dimensions, with a significant weight increase in group LILA-01 mice at the pre-patent phase of infection, when compared with control mice examined at the same time. This splenomegaly was common to other groups in the subsequent acute and intermediate stages of infection. During the transition from pre-patent and acute phase of infection there was statistically increase significant in the weight of spleens in all mice.

Microscopically, spleen tissue showed follicular hyperplasia in the white pulp. This was initially moderate, becoming intense during evolution of disease. In the red pulp, congestion was very apparent and intensified as the disease progressed. This was comparable with the hypertensive splenomegaly that is characteristic of schistosomiasis in the more advanced phase. The presence of polymorphonuclear leucocytes and eosinophyls was noted only at the acute phase of infection and reached apex at the chronic stage. S. mansoni eggs, pigment, and fibrosis were observed from the 112th day of infection and they persisted in the subsequent phases (Fig. 2B). All these findings agree with previously described histopathological alterations during the infection (Raso 2000, Cheever et al. 2002).

During the phase of egg production, the classic descriptions of low grade, irregular ulcerations of the intestines were not observed. Such lesions have been attributed not only to local action of the eggs and granulomas, but also to high immunecomplex levels in the acute phase (Raso 2000). The absence of such lesions in our studies could explain the absence of gastrointestinal bleeding in our mice; this complication has been considered as the main cause of death among infected mice in other studies (Cheever et al. 2002).

In the chronic stages of disease we noted a variable number of granulomas, most frequently in the sub-mucosa of the large intestine and in the small intestine se- rous. This was an unspecific inflammation, with mononuclear exudates and a variable number of eosinophyls. This was usually more intense in the sub mucosa and in the membranous lamina propria.

For reasons not fully explained there is, in certain cases, a deviation of the tecidual reaction to eggs and their products, and intestinal schistosomiasis acquires peculiar characteristics. In the colon, for example, we frequently observed formation of polypoidal projections, characterized by excessive conjunctive neoformation and by confluence of agglomerates of eggs and granuloma in the colon (Fig. $2 \mathrm{C}$ ). This hyperplasic form is rare among humans, with the variable incidence of 0.2 to $5 \%$ of infected individuals (Raso 2000). In addition, the literature indicates this to be found only in chronic forms of helminth infection which was not observed in our studies.

These polypoid projections were present since the acute phase in our experiment. This raises the question as to whether murine infection by the strains used in this study induced a deviation of the tecidual reaction to the eggs and their products, in this way facilitating the installation of intestinal schistosomiasis polyp forms.

Identification of the characteristics and similarities in experiments using different strains of the same etiological agent, S.mansoni, makes it possible to correlate the patterns and peculiarities in the behaviour of strains from different geographical areas.

The main histopathological findings in murine infection by PC (PARA) and LILA (MA) S. mansoni strains are compatible with the classic descriptions given in the literature by workers using different strains of the trematode.

Some features of murine infection possibly related to the strain used may be summarized as follow:

During the pre-patent phase of infection with the PC strain, there are exudative reactions in the liver, without the presence of eggs in their centers. In contrast, in mice infected with the LILA strain, eggs can be found in the reaction center. At the same stage of infection, periovular granulomas were only observed in mice of groups LILA01 and LILA-02.

Installation of the "pipe stem cirrhosis" was seen only in mice of group LILA-01, during the late phase of infection; resence of $S$. mansoni eggs occurred precociously in the lung tissue in group PC-02; precocious installation of hyperplasic form of polypoid was seen in all groups.
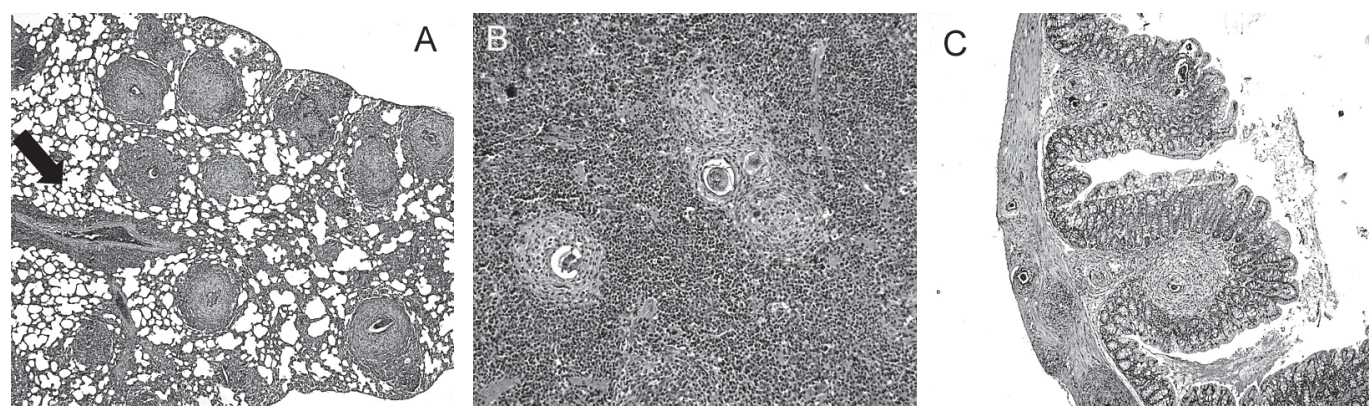

Fig. 2: histopathological findings in other tissues of experimental infection by Schistosoma mansoni. A: granuloma in lung, with arteritis (arrow), H\&E, 40×; B: concentric granuloma in spleen, H\&E, 100×; C: polypoid projections in mucosae, H\&E, 40×. 


\section{ACKNOWLEDGMENTS}

To Walter Miranda Campos for the preparation of histological sections and Dr Ralph Lainson for assistance with the English in this manuscript.

\section{REFERENCES}

Andrade ZA, Azevedo TM 1987. A contribution to the study of acute schistosomiasis (an experimental trial). Mem Inst Oswaldo Cruz 82: 311-317.

Andrade ZA, Freitas LAR 1991. Hyperplasia of elastic tissue in hepatic schistosomal fibrosis. Mem Inst Oswaldo Cruz 86: 447-456.

Andrade ZA, Sadigursky M 1985. Um estudo comparativo das cepas Feira de Santana (Bahia) e Porto Rico do Schistosoma mansoni na infecção experimental do camundongo. Mem Inst Oswaldo Cruz 80: 37-40.

Andrade ZA, Warren KS 1964. Mild prolonged schistosomiasis in mice: alterations in host response with time and the development of portal fibrosis. Trans R Soc Trop Med Hyg 58: 53-57.

Carvalho ADV, Alvarenga RJ, Melo AL 1986. Histopatologia da esquistossomose mansoni em fígado de Mus musculus infectado por amostras humanas de fase aguda e crônica da periferia de Belo Horizonte, Minas Gerais. Rev Soc Bras Med Trop 19: 84-94.

Cheever AW, Lenzi JA, Lenzi HL 2002. Experimental models of Schistosoma mansoni infection. Mem Inst Oswaldo Cruz 97: 917-940.

Coelho PMZ, Raso P, Mello RT, Toppa NH 1989. Dimensões do granuloma hepático produzido por ovos de duas linhagens geográficas do Schistosoma mansoni, no camundongo. Mem
Inst Oswaldo Cruz 84: 213-217.

Domingo EO, Warren KS 1968. Endogenous desensitization: changing host granulomatous response to schistosome eggs at diffrenet stages of infection with Schistosoma mansoni. Am J Pathol 52: 369-379.

Duvall RH, DeWitt WB 1967. An improved perfusion technique for recovering adult schistosomes from laboratory animals. Am J Trop Med Hyg 16: 483-486.

Lambertucci JR, Rayes AAM, Barata CH, Teixeira R, Gerspacher Lara R 1997. Acute schistosomiasis: report on five singular cases. Mem Inst Oswaldo Cruz 92: 631-635.

Lambertucci JR, Richard-Lima M, Serufo JC 2001. Abscesso piogênico do fígado e esquistossomose mansoni. Rev Soc Bras Med Trop 34: 601-602.

Lichtenberg FV 1962. Host response to eggs of S. mansoni: granuloma formation in the unsensitized laboratory mouse. Am J Pathol 41: 711-723.

Raso P 2000. Esquistossomose mansônica. In G Brasileiro Filho, Patologia, $6^{\mathrm{a}}$ ed., Guanabara Koogan, Rio de Janeiro, p. 1186-1207.

Silva LM, Fernandes ALM, Barbosa Jr A, Oliveira IR, Andrade ZA 2000. Significance of schistosomal granuloma modulation. Mem Inst Oswaldo Cruz 95: 353-361.

Souza Vidal MRF, Barbosa Jr AA, Andrade ZA 1993. Experimental pulmonary schistosomiasis: lack of morphological evidence of modulation in schistosomal pulmonary granulomas. Rev Inst Med Trop São Paulo 35: 423-429.

Teixeira R, Coelho PMZ, Brasileiro Filho G, Azevedo Junior GM, Serufo JC, Pfeilsticker FJ 2001. Pathogenic aspects of pyogenic liver abscess associated with experimental schistosomiasis. Am J Trop Med Hyg 64: 298-302. 
